\title{
Shared genetic influence of BMI, physical activity and type 2 diabetes: a twin study
}

\author{
S. Carlsson • A. Ahlbom • P. Lichtenstein • T. Andersson
}

Received: 19 December 2012 / Accepted: 24 January 2013 / Published online: 13 February 2013

(C) Springer-Verlag Berlin Heidelberg 2013

\begin{abstract}
Aims/hypothesis The aim of this study was to examine the long-term associations of BMI and physical activity with type 2 diabetes, and to estimate shared genetic components of these traits.

Methods We used data from the Swedish Twin Registry on 23,539 twins born 1886-1958 who answered questionnaires between 1967 and 1972 and were followed up until 1998. The risk of type 2 diabetes in relation to BMI and physical activity was assessed by Cox regression. Structural equation models were used to estimate genetic and environmental variance components and genetic correlations.

Results The risk of type 2 diabetes increased with BMI (HR $1.32[95 \%$ CI $1.29,1.35]$ per $\mathrm{kg} / \mathrm{m}^{2}$ ) and decreased with physical activity (HR 0.56 [95\% CI $0.39,0.80]$ for high vs low). Heritability was estimated to be $77 \%$ (95\% CI $54 \%$, $83 \%$ ) for type 2 diabetes, $65 \%$ (95\% CI 58\%, $73 \%$ ) for BMI, and $57 \%(95 \%$ CI $47 \%, 67 \%)$ for physical activity. The genetic correlation with type 2 diabetes was 0.43 (95\% CI $0.31,0.58)$ for BMI and $-0.23(95 \% \mathrm{CI}-0.46,0.02)$ for physical activity, implying that $18 \%(95 \%$ CI $9 \%, 34 \%)$ of the genetic influence on type 2 diabetes is shared with BMI and $5 \%(95 \%$ CI $0 \%, 20 \%)$ with physical activity.

Conclusions/interpretation Indications of shared genetic effects are found for BMI and type 2 diabetes, which suggests that these traits are partly influenced by the same genetic factors. In contrast, our findings suggest that the
\end{abstract}

S. Carlsson $(\bowtie) \cdot$ A. Ahlbom $\cdot$ T. Andersson

Department of Epidemiology, Institute of Environmental

Medicine, Karolinska Institutet, 17177 Stockholm, Sweden

e-mail: sofia.carlsson@ki.se

P. Lichtenstein

Department of Medical Epidemiology and Biostatistics,

Karolinska Institutet, Stockholm, Sweden genes related to physical activity are essentially different from those associated with type 2 diabetes.

Keywords BMI $\cdot$ Epidemiology $\cdot$ Genetic $\cdot$ Physical activity $\cdot$ Twin study $\cdot$ Type 2 diabetes
Abbreviations
DZ Dizygotic
MZ Monozygotic

\section{Introduction}

One of the major health hazards to people who are overweight and/or sedentary is an increased risk of type 2 diabetes $[1,2]$. These traits also have strong genetic components; twin studies indicate heritability of $26-73 \%$ [3] for type 2 diabetes, $50-90 \%$ for BMI [4] and $27-70 \%$ for physical activity [5]. If the same genetic factors that promote type 2 diabetes are related to BMI or physical activity, part of these associations may reflect a common genetic origin, rather than a causal effect.

Few studies have addressed this issue, but recent findings from the Finnish Twin Cohort indicate that one-fifth of the genetic influence on type 2 diabetes is shared with BMI [3]. No corresponding estimates were reported for physical activity, but it was suggested that the association with type 2 diabetes is largely independent of genetic influence [6]. Only two other studies, based on a small number of twins, have addressed these issues [7, 8]. Replications and expansions in this field are thus needed.

Our aim was to simultaneously investigate the association between BMI, physical activity and type 2 diabetes in relation to genetic factors, and to estimate shared genetic influences on these traits, using data from the Swedish Twin Registry, one of the world's largest twin studies. 


\section{Methods}

\section{The Swedish Twin Registry}

We used data from the Swedish Twin Registry consisting of same-sex twin pairs born 1886-1958 [9]. Baseline information on height, weight, health and lifestyle factors (e.g. physical activity, alcohol consumption, occupation and smoking) were obtained by questionnaires administered between 1967 and 1972.

\section{Follow-up}

Between 1998 and 2002, these twins were screened for disease, including diabetes in the SALT (Screening Across Lifespan Twin) Study [9]. Data were collected via telephone by trained interviewers. Among 42,334 twins eligible for the present study (complete baseline information on BMI and physical activity and free from diabetes), 9,659 (22.8\%) died before follow-up. Of the remainder, we were able to follow-up $72 \%(n=23,539)$ with regard to diabetes. Of these, 1,068 developed diabetes, and 1,021 (96\%) were classified as having type 2 diabetes either because they responded that, according to their doctor, they had 'oldage diabetes', 'type-2 diabetes' or 'non-insulin-dependent diabetes' ( $n=785,77 \%$ ) or, if they did not know their type, because they reported age at onset to be $>35$ years $(n=236$, $23 \%$ ). Participants who did not fit these criteria were excluded.

\section{Measurements}

Zygosity was determined on the basis of questions on childhood resemblance. When compared with DNA testing, this method has been proven to correctly classify more than $95 \%$ of twins [9]. BMI $\left(\mathrm{kg} / \mathrm{m}^{2}\right)$ was calculated on the basis of baseline questionnaire information on height and weight and categorised according to WHO classification. Information on physical activity was collected by a question on average leisure time physical activity. For participants born 18861925, response options were: 1 , 'hardly any'; 2 , 'some light exercise'; 3, 'exercise regularly'; 4, 'exercise a lot' (categories 3 and 4 were collapsed in the analyses). For participants born 1926-58, there were seven response options, which were combined into three: low (exercise 'almost never' to 'hardly ever'), moderate ('very little' to 'quite a bit') and high ('a lot' to 'very much') physical activity.

\section{Analyses}

Cohort analyses We calculated HRs of type 2 diabetes in relation to BMI and physical activity in an ordinary cohort analysis, where we used Cox proportional hazards models with a frailty component to handle within-pair dependences (SURVIVAL 2.36-14 package with Coxph in $\mathrm{R}$ 2.15.0). Person-years were accumulated from age at baseline until age of diabetes onset or age at end of follow-up, whichever came first. Adjustment for smoking, occupation and alcohol consumption had limited influence on the HRs $(<5 \%$ change), and therefore these factors were not included in the final model.

Heritability analyses Structural equation models estimated how much of the variance in diabetes could be explained by additive genetic effects (A), common environmental effects (C) and unique environmental effects (E) in a univariate ACE threshold model. Two multivariate Cholesky ACE threshold models for BMI/diabetes and physical activity/diabetes were used to extract estimates of the genetic $\left(r_{\mathrm{g}}\right)$ and environmental $\left(r_{\mathrm{e}}\right)$ correlations between these traits. No additional covariates were used in any of the models and only complete pairs. All analyses were performed in MX 1.7.

\section{Results}

\section{Cohort analyses}

During follow-up, the cumulative incidence of type 2 diabetes was $4.3 \%$ (Table 1). Mean age at onset was 58.7 and a higher proportion of men $(5.1 \%)$ than women developed diabetes (3.7\%). In cohort analysis, based on 23,539 twins, overweight and obesity were associated with an increased risk of type 2 diabetes, whereas physical activity was associated with a reduced risk, compared with participants with normal weight and low physical activity, respectively (Table 2). These associations were seen in separate analyses of monozygotic (MZ) (HR per kg/m² 1.37 [95\% CI 1.31, 1.43] and HR for high vs low physical activity 0.66 [95\% CI $0.34,1.26])$ and dizygotic (DZ) (HR per $\mathrm{kg} / \mathrm{m}^{2} 1.28$ [95\% CI 1.24, 1.31] and HR 0.53 [95\% CI 0.35, 0.80]) twins, in men and women, and persisted after adjustment for BMI/physical activity (results not shown).

\section{Heritability analyses}

The variance component analyses were based on 4,183 complete twin pairs including 619 cases of diabetes (Table 1). The increased risk of type 2 diabetes conferred by overweight/obesity and physical inactivity was confirmed in cohort analysis of this subset of twins (Table 2). Structural equation modelling indicated that additive genetic effects contributed substantially to the variation in type 2 diabetes (77\%), BMI (65\%) and physical activity (57\%) (Table 3). The remaining variation in diabetes was attributed to unique environmental factors. BMI was influenced by shared (17\%) as 
Table 1 Descriptive data of the twins used in the different analyses

\begin{tabular}{|c|c|c|c|c|}
\hline \multirow[t]{2}{*}{ Characteristic } & \multicolumn{2}{|c|}{ Cohort analyses (all twins) } & \multicolumn{2}{|c|}{ Variance component analyses (complete pairs) } \\
\hline & $\mathrm{MZ}$ & DZ & MZ & $\mathrm{DZ}$ \\
\hline No. of individuals & 9,292 & 14,247 & 7,064 & 9,668 \\
\hline Men $(\%)$ & 44.01 & 45.62 & 42.13 & 43.57 \\
\hline Age at baseline (years) & $31.49(10.93)$ & $32.33(11.17)$ & $30.17(9.97)$ & $30.83(10.32)$ \\
\hline Age at end of follow-up (years) & $58.66(10.62)$ & $59.53(10.93)$ & $57.35(9.50)$ & $58.02(9.90)$ \\
\hline BMI $\left(\mathrm{kg} / \mathrm{m}^{2}\right)$ & $21.83(2.83)$ & $22.09(2.94)$ & $21.64(2.77)$ & $21.87(2.88)$ \\
\hline High physical activity (\%) & 11.20 & 10.19 & 11.51 & 9.95 \\
\hline No. of incident cases of diabetes & 405 & 616 & 263 & 356 \\
\hline Cumulative incidence $(95 \% \mathrm{CI})$ & $0.044(0.040,0.048)$ & $0.043(0.040,0.047)$ & $0.037(0.030,0.044)$ & $0.037(0.032,0.042)$ \\
\hline
\end{tabular}

Results are presented as mean (SD) unless indicated otherwise

well as unique (18\%) environmental factors, whereas nonshared environmental factors appeared to be more important for variation in physical activity (34\%).

We estimated a moderately strong correlation between the genetic factors for type 2 diabetes and BMI $\left(r_{\mathrm{g}} 0.43\right.$ [95\% CI 0.31, 0.58] and $r_{\mathrm{g}}{ }^{2} 19 \%$ [95\% CI 9\%, 34\%]), suggesting that about one-fifth of the genetic influence is shared (Table 3). For physical activity, the shared genetic influence with type 2 diabetes was limited $\left(r_{\mathrm{g}}-0.23\right.$ [95\% CI $0.02,-0.46]$ and $r_{\mathrm{g}}{ }^{2} 5 \%$ [95\% CI 0\%, 20\%]). There was also a moderately strong correlation between the environmental components for BMI and type 2 diabetes $\left(r_{\mathrm{e}} 0.39\right.$ [95\% CI 0.22, 0.55] and $r_{\mathrm{e}}^{2} 15 \%$ [95\% CI 5\%, 31\%]), which was negligible with physical activity.

\section{Discussion}

The association between overweight/obesity, physical activity and type 2 diabetes documented previously [1, 2] was confirmed in our twin study, as was the strong genetic influence on these traits [3-5]. We estimated the shared genetic influence of BMI and type 2 diabetes to be $19 \%$, which indicates that these traits are, in part, influenced by the same genes. This confirms findings based on Finnish, Indian and Australian twins [6-8]. There are some potential pleiotropic genes, including the FTO gene, which has been linked to BMI as well as type 2 diabetes [10]. However, currently identified genes can only explain about $10 \%$ of the heritability of type 2 diabetes, and a wide range of presently unidentified genes could be involved.

In contrast, we estimated that only $5 \%$ of the genetic influence of physical activity and type 2 diabetes was shared. This suggests that the strong genetic influence of physical activity $(57 \%)$ is related to genes that are essentially different from those related to type 2 diabetes. To the best of our knowledge, the shared genetic component of physical activity and type 2 diabetes has not been estimated previously, but these findings are supported by a report from the Finnish Twin Cohort [6].

In our study, cases of diabetes were identified by interview several years after the baseline investigation. Loss to

Table 2 BMI, physical activity and the risk of type 2 diabetes

\begin{tabular}{|c|c|c|c|c|}
\hline \multirow[t]{2}{*}{ Variable } & \multicolumn{2}{|l|}{ All twins } & \multicolumn{2}{|l|}{ Complete pairs } \\
\hline & Cases/person-years & $\mathrm{HR}(95 \% \mathrm{CI})$ & Cases/person-years & $\mathrm{HR}(95 \% \mathrm{CI})$ \\
\hline \multicolumn{5}{|l|}{ BMI } \\
\hline Underweight $\left(<18.5 \mathrm{~kg} / \mathrm{m}^{2}\right)$ & $16 / 59,347$ & $0.57(0.34,0.95)$ & $10 / 46,958$ & $0.45(0.23,0.87)$ \\
\hline Normal weight $\left(18.5-24.9 \mathrm{~kg} / \mathrm{m}^{2}\right)$ & $499 / 493,378$ & 1 & $321 / 354,028$ & 1 \\
\hline Overweight $\left(25-29.9 \mathrm{~kg} / \mathrm{m}^{2}\right)$ & $414 / 80,614$ & $3.94(3.36,4.61)$ & $233 / 49,961$ & $3.70(3.00,4.55)$ \\
\hline Obesity $\left(\geq 30 \mathrm{~kg} / \mathrm{m}^{2}\right)$ & $92 / 6,485$ & $21.98(15.40,31.35)$ & $55 / 3,944$ & $22.42(14.15,35.54)$ \\
\hline Per $\mathrm{kg} / \mathrm{m}^{2}$ & & $1.32(1.29,1.35)$ & & $1.32(1.28,1.36)$ \\
\hline \multicolumn{5}{|l|}{ Physical activity } \\
\hline Low & $135 / 68,991$ & 1 & $91 / 46,898$ & 1 \\
\hline Moderate & $824 / 502,120$ & $0.77(0.61,0.96)$ & $492 / 359,065$ & $0.70(0.53,0.93)$ \\
\hline High & $62 / 68,713$ & $0.53(0.37,0.75)$ & $36 / 48,928$ & $0.51(0.32,0.79)$ \\
\hline
\end{tabular}




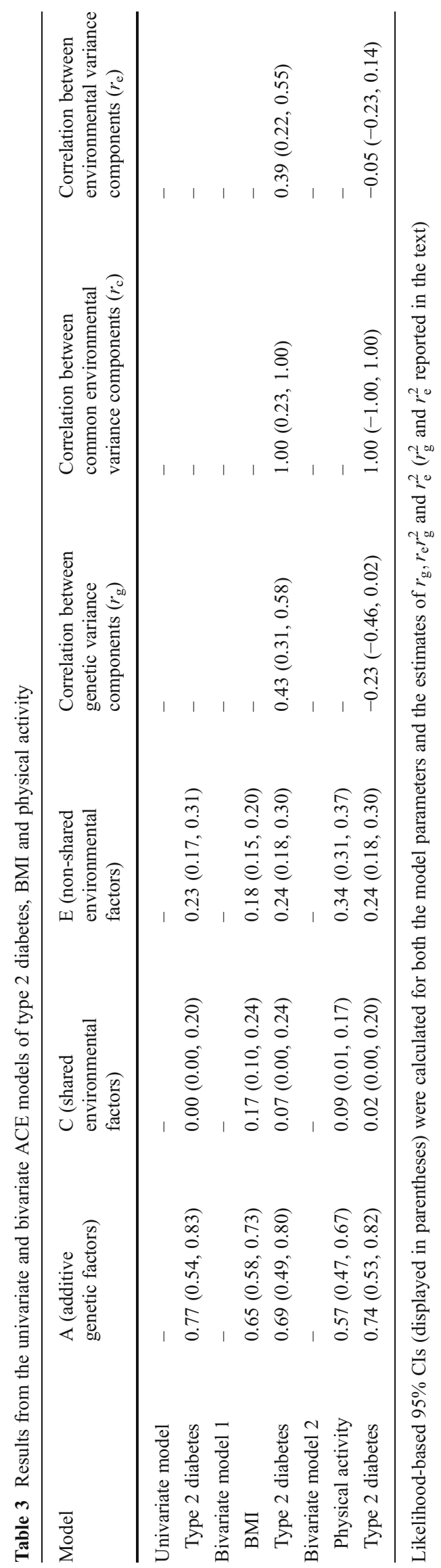


follow-up may lead to underestimation of the association between BMI/physical inactivity and diabetes, but is unlikely to influence the heritability estimates as long as MZ and $\mathrm{DZ}$ twins do not differ in this respect. We have no reason to believe otherwise since death rates did not differ by zyogosity. Cases of undiagnosed diabetes will also be missed. It seems possible that undiagnosed diabetes is less common among siblings of diabetic twins, but this will not lead to inflated heritability estimates as long as MZ and DZ twins do not differ in this respect. This seems unlikely, since the cumulative incidence of diabetes was similar in $\mathrm{MZ}$ and $\mathrm{DZ}$ twins. Given that type 2 diabetes is by far the most common form of diabetes, the implication of any misclassification of diabetes type in our interpretations is probably modest. There is probably some misclassification of twins by zygosity, which may have diluted the estimated genetic influences. A further limitation was the crude information on physical activity and BMI. However, the association with type 2 diabetes that we observed was very similar to results seen in studies with more detailed information [1,2]. Also, the estimated genetic component of BMI, physical activity and type 2 diabetes was within the range of previous studies [3-5].

We conclude that shared genetic factors contribute to the association between BMI and type 2 diabetes, whereas genetic factors related to physical activity seem to be essentially distinct from those related to type 2 diabetes.

Funding The Swedish Twin Registry is funded by a grant from the Department of Higher Education, the Swedish Scientific Council.

Duality of interest The authors declare that there is no duality of interest associated with this manuscript.

Contribution statement SC was responsible for writing the paper, contributed to developing the objective of the study and interpreting results, and had full access to all the data and takes responsibility for the integrity of the data and the accuracy of the data analysis. TA contributed to developing the objective of the study, writing and revising the paper, and was responsible for the statistical approach and analysing the data and interpreting results. PL contributed to developing the objective of the study, interpreting the results and writing the paper. AA contributed to developing the study objective, interpreting the data and writing the paper. All authors have seen and approved the final version of the manuscript.

\section{References}

1. Jeon CY, Lokken RP, Hu FB, van Dam RM (2007) Physical activity of moderate intensity and risk of type 2 diabetes: a systematic review. Diabetes Care 30:744-752

2. Abdullah A, Peeters A, de Courten M, Stoelwinder J (2010) The magnitude of association between overweight and obesity and the risk of diabetes: a meta-analysis of prospective cohort studies. Diabetes Res Clin Pract 89:309-319

3. Lehtovirta M, Pietiläinen KH, Levälahti E et al (2010) Evidence that BMI and type 2 diabetes share only a minor fraction of genetic variance: a follow-up study of 23,585 MZ and DZ twins from the Finnish Twin Cohort Study. Diabetologia 53:1314-1321

4. Maes HH, Neale MC, Eaves LJ (1997) Genetic and environmental factors in relative body weight and human adiposity. Behav Genet 27:325-351

5. Vink JM, Boomsma DI, Medland SE et al (2011) Variance components models for physical activity with age as modifier: a comparative twin study in seven countries. Twin Res Hum Genet $14: 25-34$

6. Waller K, Kaprio J, Lehtovirta M, Silventoinen K, Koskenvuo M, Kujala UM (2010) Leisure-time physical activity and type 2 diabetes during a 28 year follow-up in twins. Diabetologia 53:25312537

7. Condon J, Shaw JE, Luciano M, Kyvik KO, Martin NG, Duffy DL (2008) A study of diabetes mellitus within a large sample of Australian twins. Twin Res Hum Genet 11:28-40

8. North KE, Williams JT, Welty TK et al (2003) Evidence for joint action of genes on diabetes status and CVD risk factors in American Indians: the Strong Heart Family Study. Int J Obes Relat Metab Disord 27:491-497

9. Lichtenstein P, Sullivan PF, Cnattingius S et al (2006) The Swedish Twin Registry in the third millennium: an update. Twin Res Hum Genet 9:875-882

10. Hertel JK, Johansson S, Sonestedt E et al (2011) FTO, type 2 diabetes, and weight gain throughout adult life: a meta-analysis of 41,504 subjects from the Scandinavian HUNT, MDC, and MPP studies. Diabetes 60:1637-1644 